
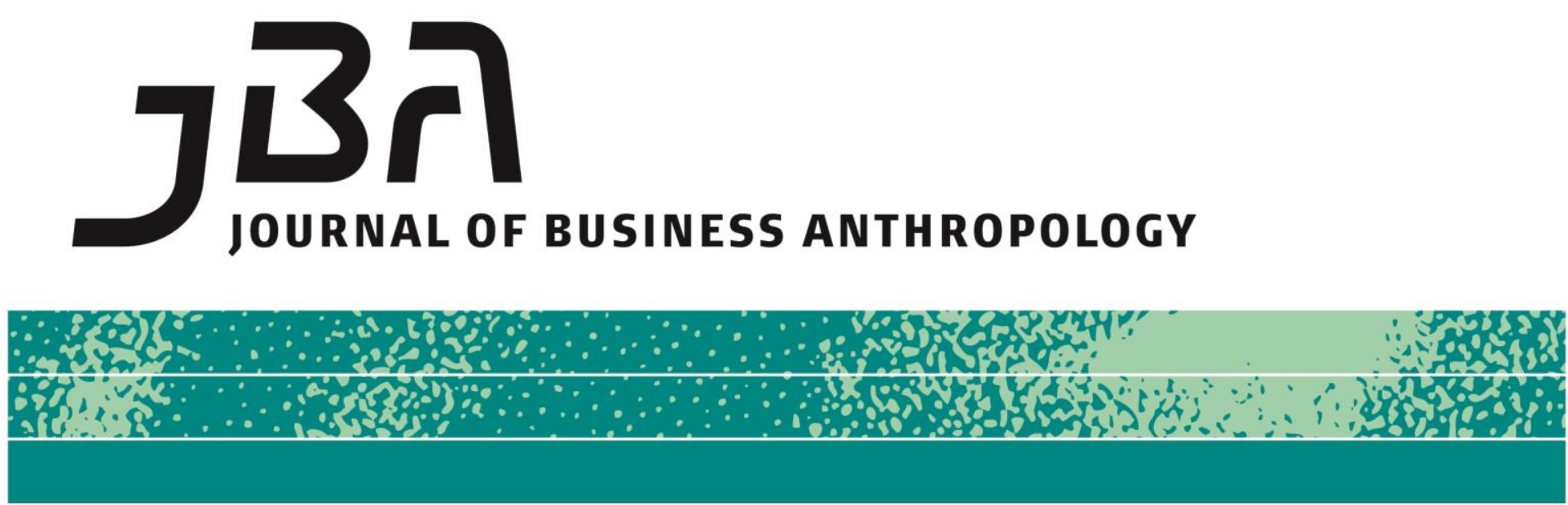

\title{
Lost in Translation? Ethics and Ethnography in Design Research
}

\author{
Christine Miller
}

\begin{abstract}
It has long been the case that ethnographic techniques have been appropriated by other disciplines. In particular, designers have employed ethnography and naturalistic inquiry in research for private and public sector client projects. As ethnographic methods have diffused to other fields questions have been raised about whether the ethical concerns that have become engrained over time in anthropological field work have carried over along with the methodology. This article explores how ethical considerations are addressed (or not) in ethnographic-style research, specifically within the field of design. A review of secondary sources and interviews with three practicing designers provide insight as to the shifts that have occurred over time within design and how these changes have impacted design research and practice, specifically in relation to ethical issues.
\end{abstract}

Page 1 of 17

\section{Keywords}

Ethics, ethnography, design research 


\section{Introduction}

This article was first presented in the session "Ethics in Business Anthropology" at the American Anthropological Association Annual Meeting in 2012 themed 'Borders and Crossings'. The goal of this session was to examine issues around ethics and ethical challenges related to the movement of anthropological practice into business and commercial enterprise and in operating between academia and business. Historically, ethics has been a primary concern within anthropology. Vigilance around ethics is constant and pervasive, from the education and training of students throughout all aspects of professional practice. The focus on ethics was especially relevant in the fall of 2012 given the finalization of the latest revision of the AAA Code of Ethics ${ }^{1}$ that was triggered by concerns around complex ethical questions raised by the increasing engagement of applied anthropologist in domains outside what have been considered as the discipline's 'traditional' fields.

The purpose of this article is to examine whether a concern for ethical issues has accompanied the diffusion of ethnography, particularly with the adoption of ethnographic methods within the field of design and design research. The intent is to show how the history of design has shaped the stance on ethical issues and to provide insight as to how the meaning of ethics is negotiated within the field, as well as how the awareness of ethics is changing as the field evolves. This approach offers one perspective on the question raised in the 2012 Annual Meeting of the American Anthropological Association: What is lost, gained or in need of reevaluation in the interstitices of border crossings?

This examination of ethics in design and design research is grounded in my experience as an anthropologist teaching in a U.S.-based art and design school, which has been my field of study and practice for the past seven years. As in any anthropological study, my immersion in design as a 'non-designer' put me in the position of simultaneously being an apprentice and an educator, as well as a researcher. Completing a bachelor's degree in studio art provided the fundamentals in fine art. However, designers maintain that the relationship between design and art exists at a rudimentary level, initially because design was differentiated as an "applied art" and later by its professionalization and ties to industry. The separation between art and design has become even more pronounced as the emphasis within design has shifted from tangible objects and craft to a focus on intangibles, concepts, and process.

Drawing on various secondary sources, personal experience, and interviews with design practitioners, this research is guided by three primary questions: (1) Have ethical concerns diffused along with ethnographic methods in design research? (2) Are ethics integrated into the education and training of designers? (3) What ethical guidelines, if

${ }^{1}$ http://www.aaanet.org/profdev/ethics/ 
any, are employed by practicing designers in planning and conducting research with human subjects? The inquiry led to questions regarding the relationship between the shift in focus within design from 'object' to 'user', and a heightened sensitivity regarding ethics.

\section{The diffusion of the ethnographic method}

In 2000 Christina Wasson noted that "The application of anthropological methods has become strikingly popular in the field of industrial design." Later in the article she wonders whether or not in ten years ethnography will be regarded as a "short-lived fashion from the turn of the millennium." (Wasson 2000:384) Today, thirteen years after Wasson's article, ethnographic-style methods within design research have far from gone out of fashion. Instead, they attained a central role in design - so much so that most young designers have never known of "a world where design happened without ethnography." It is also still the case that designers refer to the brand of naturalistic inquiry that they practice as 'ethnography' (Wasson 2000) in spite of the vast differences in the ways in which the methodology is conceptualized and practiced by designers.

Have ethical considerations, so deeply embedded in the education of anthropologists and in professional practice, diffused along with the ethnographic method? The core principles that anthropologists consider when conducting research can be found on the American Anthropological Association (AAA) website, ${ }^{2}$ where the topic of professional ethics is included under 'professional development'. In this section one can read the May 1971 'Statement of Ethics: Principles of Professional Responsibility" that was written "to clarify professional responsibilities in the chief areas of professional concerns to anthropologists." The 1971 statement includes two earlier statements: the December 1948 "Resolution on Freedom of Publication" and the March 1967 "Statement on Problems of Anthropological Research and Ethics."

Six areas of responsibility are addressed in the May 1971 Statement on Ethics: (1) relations with those studied; (2) responsibility to the public; (3) responsibility to the discipline; (4) responsibility to students; (5) responsibility to sponsors; and (6) responsibility to one's own government and to host governments. These six areas are reflected in somewhat different language in subsequent versions in June 1998, 2009 and - most recently - the 2012 "Statement on Ethics: Principles of Professional Responsibility" where the focus is on 'core principles' that address ethical concerns that are "shared across subfields and contexts of practice" (AAA 2012).

Seven core principles are documented in the 2012 statement: (1) Do no harm; (2) Be open and honest regarding your work; (3) Obtain

\footnotetext{
${ }^{2}$ http://www.aaanet.org/profdev/ethics/
} 
informed consent and necessary permissions; (4) Weigh competing ethical obligations due collaborators and affected parties; (5) Make your results accessible; (6) Protect and preserve your records; and (7) Maintain respectful and ethical professional relationships. These principles embody the primary ethical concerns related to anthropological research. The fact that they have evolved over time reflects the changes in anthropological practice, a consideration that becomes important in investigating the diffusion of the ethnographic method to the field of design.

\section{Lost in translation?}

Debates over whether or not designers have actually adopted 'ethnography' occur less often these days. However, concerns for how anthropologists are engaging in business anthropology and the implications for ethics run high. The deep sensitivity for and concern with ethics within anthropology grew out of the history of the discipline. Since they don't share the same history, it is unreasonable to expect designers to adopt the same sensitivities and concerns. However, it would be incorrect to assume that those who employ ethnographic methods have no regard for ethics. In fact, there is ample evidence to argue that designers have clearly articulated ethical concerns that reflect changes in the field over time, the particular aspects of their practice, and the variety of contexts in which they work. Examples will be cited from a variety of sources that suggest both similarities and differences relative to ethics that are emerging in the profession as designers adapt and recontextualize ethnography to their practice.

\section{Two disciplines; two histories}

Charles and Ray Eames ${ }^{3}$, creators of the Eames Low Wood Chair (LWC), described design as "a plan for arranging elements in such a way as to best accomplish a particular purpose" (Eames 1972; Neuhart, et al. 1989) This definition is broad enough to encompass the design of both tangible and intangible artifacts and anticipates the evolution of the field. It does not, however, explicitly acknowledge the realm of the social, which remains implicit. In contrast to anthropology's unwavering focus on situated human social and cultural contexts, for design the 'plan' itself is the central focus of attention.

Within design the shift in focus from 'object' to 'user' can be traced to the Ulm School ${ }^{4}$ (1953-1968), which followed in the steps of the

\footnotetext{
${ }^{3}$ American designers Charles and Ray Eames are known for their contributions to modern architecture and furniture. They are especially notable for the design of the Eames Lounge Chair Wood (LCW).

4 The Ulm School (1953-1968) was greatly influenced by the Bauhaus (1919-

1933). In 1961 two Ulm graduates carried the Ulm model to Auburn University
} 
Bauhaus movement ${ }^{5}$. The user-centered design approach required that designers immerse themselves directly in the users' work and social contexts, "thereby giving them the richest possible data to invent from" (Holtzblatt and Jones 1995). Anthropologists tended to have significant influence in design's turn to the 'user' because of the clear advantage of the ethnographic approach. The anthropological perspective intrinsically challenges assumptions and thus problematizes any area of investigation, opening the way to fresh insights and potential innovations. An anthropological approach to a design study would seek to discover the fullest range of factors operating within the study context, such as issues in the social, technical, economic, and political realms that might not be obvious or immediately relevant to someone intent on designing the next iteration of a product or service.

Christina Wasson (2000) has documented the trajectories that brought the fields of anthropology and design together. As designers and well known design firms began to adopt the use of ethnographic methods in the 1980s and 1990s they attracted significant attention from the popular business and design press (Wasson 2000). Ethnographic-style methods were re-contextualized, merged, and adapted to design practice. The introduction of ethnography coincided with and facilitated the shift in focus from the 'object' to the 'user'. Over time designers have developed a distinctive approach to naturalistic inquiry and qualitative research that is reflected in their design methodologies. For example, Contextual Inquiry (or CI), the first component in the process of Contextual Design ${ }^{6}$, was developed in response to the challenge "to design new kinds of systems rather than iterating existing systems" (Beyer and Holtzblatt 1998).

Many designers approach their work from the perspective of systems thinking, which today includes not only technical systems, but also social systems. Although this perspective is shared with anthropologists, the factors that have shaped the evolution of each discipline are different and have implications for the position occupied by ethical concerns. Within anthropology, the concern for ethics is deeply rooted in past ties to colonialism and the subsequent recognition of the "myriad of ethical quandaries inflected in different ways by the contexts

where the user-centered systems design process was infused into the design curriculum. http://www.hfg-archiv.ulm.de/english/

${ }^{5}$ Bauhaus (1919-1933) is described as "the first academy for design in the world." It was a response to the Industrial Revolution and dehumanization, an attempt to keep art and craft from being lost to mass production.

http://bauhaus-online.de/en

${ }^{6}$ Ethnography and ethics do not appear as topics in the index of Beyer and Holtzblatt's (1998) text. However, several works referencing ethnography are included in the reference section. For example "Presenting Ethnography in the Requirements Process" which was included in the proceedings of the second IEEE International Symposium on Requirements Engineering held in York, UK (March 27-29). 
in which they [anthropologists] work and the kinds of issues they address" (AAA 2012). Design has evolved from its roots in craft and its history as a 'handmaiden of industry'. This history has engendered selfreflection, which came earlier in anthropology and only more recently to design, as global events have converged to raise environmental issues and rampant consumerism as serious concerns.

The debate within the academy around the diffusion of ethnographic-style research to other fields and professions has focused on two main points. First, there is the question of whether what is being practiced is actually ethnography. Secondly, and perhaps less explicit, are concerns about whether ethics are given sufficient attention in the practice of ethnography by non-anthropologists. For anthropologists who work with designers or work in the field of design, there is no question that contextual inquiry (CI) and ethnography as practiced in anthropology are fundamentally different methodologies. Although they share an intense interest in the social realm, the purposes of the designer and the anthropologist are distinctively different. It follows that the ways in which designers have dealt with ethics in their practice are also distinct from those of anthropologists.

\section{Ethics in client-based research}

The initial goals of any design study are determined by the requirements of the project as defined by the sponsor or client: the initial conceptualization of the problem to be solved ${ }^{7}$. Generally speaking, if the study involves research with human subjects most design firms and organizations conducting in-house design research will utilize a subcontractor to assemble a pool of study participants, from which the final selection of subjects is made. Study participants are rarely recruited by the design team or firm. Rather, they are selected through a series of screening questions ${ }^{8}$, which are designed by the research team for a particular study. Prior to their participation, individuals sign a formal contract that includes information about the study, the terms of engagement, and the compensation to be received by an individual for participating as a research subject. Included in this agreement is language that explains how data collected through interviews, photos, or videos will be used. Typically this contract constitutes informed consent. From this point on, it is the job of the research team members (often including anthropologists) to establish a relationship and rapport with the study

\footnotetext{
${ }^{7}$ A deep description encompassing all the nuances and variations of how design field research is conducted is beyond the scope of this article. The general overview of the process of setting up a study provided here was corroborated by several practicing designers.

8 Research screeners are questions that precede survey questions. They are designed to identify whether or not a respondent fits the target demographic of the study, for example single mothers with at least two children under five.
} 
participants.

Various ethnography-inspired methods such as the 'drive-along' are likely to be used in data collection for design studies. These methods might include traditional interviews, passive or participant observation, shadowing, contextual inquiry (observation in situ that can include intermittent questioning), photo journals, video, or focus groups. In situations where there is direct engagement with study participants who are not under contract, informed consent might be sought through a written consent form that enables the inclusion of data in the project.

A distinguishing characteristic of design research is that field work proceeds very rapidly. Primary research is time-intensive and costly. Many clients are unwilling to fund field research since they believe that they have all the primary data needed (usually market studies) to complete the project. Consequently, design field research is extremely abbreviated, in comparison to traditional anthropological studies, a fact which poses an initial challenge to anthropologists who go through a process of unlearning and relearning to adjust their field practices when they join design research teams. The established practice of outsourcing that is, the practice of using vendors to recruit and screen study participants - can pose serious questions for anthropologists. For example, how well have participants been informed about the purpose of the study? Do they know what kinds of data will be collected and how they will be collected? Have they been informed about how data will be used, stored, how long they will be held and whether they will be destroyed? Are they made aware of their rights, if any, to access the study findings? Since most corporate research is considered proprietary, the chances are that participants will never know to what end their data are used. For anthropologists, making the study accessible to a wider audience, per the AAA Statement of Ethics, ${ }^{9}$ presents problems, since study data and findings need to be reviewed by corporate attorneys to determine what information, if any, can be shared outside the organization.

\section{Ethics in the field of design}

The emergence of ethics as an area of concern has been a gradual process, influenced by factors within the field of design itself, as well as externally by shifts in social consciousness. The history of design suggests that the current focus on 'the user' is actually a return of sorts, as designers have become more concerned with the social context into which their designs are introduced. As mass manufacturing replaced one-of-a-kind craft production, design became a professional occupation. The design of objects removed from their social context came about gradually as the psychological and physical distance between designers and users was

9 Principle (5) in the 2012 statement: make your results accessible. 
widened by layers of management. The designer, the output of production, ${ }^{10}$ and the end user of the product could be literally worlds apart. The consequences brought about by objects that were outputs of mass production were not perceived to be the responsibility of the individuals who designed them. The responsibility for a defective item, such as a toy or a car, rested with the firm, not with the individual who designed the product. This has changed as public attention to large-scale environmental and social problems has increased. The longest practicing of the designers who were interviewed for this article noted the first Earth Day in 1970 as the key event that began to raise their awareness as designers about their role in the present system of mass production and consumption.

Another factor that is influencing conversations about ethics in design is the broader definition of what constitutes a 'designer'. As design has evolved from an occupation focused on making tangible 'things' to one of designing intangibles - services, processes, interactions and experiences - awareness of the central role of social context has increased. This has opened the way for individuals who might not be considered designers (or who consider themselves as designers) in the traditional sense to self-identify and be recognized as designers. Anthropologists who work in corporate settings bring with them sensitivity to ethical issues. Cefkin (2010:18) notes that:

In all areas of research, whether for primarily academic, policy, or commercial interests, issues of ethics abound. Ethical issues infuse every aspect of corporate ethnography as well, from the very constitution and formation of the research agenda to the nature of fieldwork encounters.

However, this sensitivity to ethical issues may not be shared by their team mates or colleagues (Cefkin 2010).

Ethics in design today takes several forms. The physical and psychological distance between designers and users has diminished as designers have become directly engaged in field research. Designers are beginning to feel a sense of responsibility for the products they design. New areas of concern beyond the traditional concerns for their clients' proprietary information and design plagiarism appear in discourse within the field. These concerns range from product safety to the role of designers in the environmental impact of mass production. Internal and external recognition of the power of design to influence human behavior has raised concerns about the various roles designers have played, for example, in promoting overconsumption, and in shaping concepts of identity and beauty.

Within the field of design ethical concerns are currently reflected in three areas: standards of professional behavior, issues related to working

10 Final products often bear little resemblance to the original design concept. 
for specific clients or in specific industries - for example, tobacco, fire arms, and alcohol - and wide-ranging issues about the tangible and intangible impacts of design on the environment and on specific social groups and cultural contexts.

\section{Standards of professional behavior}

Professional associations such as the American Institute of Graphic Arts ${ }^{11}$ (AIGA) and Industrial Designers Society of America ${ }^{12}$ (IDSA) provide guidance to design practitioners. Standards of professional practice were the initial area of concern in the field of design. For example, the AIGA's Design Business + Ethics series (2009a), first published in 2001, "was created to establish consistent professional standards and define the relationship among designers, clients and content." The mission of the AIGA "includes educating designers, clients and the public about ethical standards and practices governing design."

The IDSA has a "Code of Ethics", which includes five Fundamental Ethical Principles and seven Articles of Ethical Practice. ${ }^{13}$ According to the IDSA, the Code of Ethics is based on the recognition "that industrial designers affect the quality of life in our increasingly independent and complex society; that responsible ethical decision making often requires conviction, courage and ingenuity in today's competitive business context" (IDSA 2010).

\section{From "Can we?" to "Should we?"}

The ethical questions that designers face have changed with a growing sense of personal responsibility for the impact and consequences of their work. Informal conversations, like those that convene around blog posts, reveal concerns about emerging ethical issues. David Airey ${ }^{14}$ is a blogger and graphic designer who specializes in design brand identities. In 2007 he posted the question: "how much do ethics affect your design practices?" His post generated dozens of comments and provided a forum

\footnotetext{
11 "Founded in 1914 as the American Institute of Graphic Arts, AIGA remains the oldest and largest professional membership organization for design and is now known simply as 'AIGA, the professional association for design."' http://www.aiga.org/About/

12 "The Industrial Designers Society of America promotes the practice and education of Industrial Design." http://www.idsa.org/

13 "Recognizing that industrial designers affect the quality of life in our increasingly independent and complex society; that responsible ethical decision making often requires conviction, courage and ingenuity in today's competitive business context: We, the members of the Industrial Designers Society of America, will endeavor to meet the standards set forth in this code, and strive to support and defend one another in doing so." http://www.idsa.org/content/content1/code-ethics

14 http://www.davidairey.com/
} 
for discussions about the types of ethical decisions that confronted designers. The post was updated in 2010, 2011, and 2012.

Wide-ranging issues about the impacts of design on the environment, on specific social groups and cultural contexts surfaced in July 2012 when Bruce Nussbaum, design commentator and Professor of Innovation and Design at Parsons New School of Design, posted an essay on Fast Company's blog entitled "Is Humanitarian Design the New Imperialism?" Nussbaum's post raised a firestorm when he questioned the motivations and benefits of "Humanitarian Design" through projects such as Emily Pilloton's Design Revolution Road Show (Project H), initiatives from IDEO, the Acumen Fund, and One Laptop per Child (Nussbaum 2010). The mission statement of Project $\mathrm{H}^{15}$ ends with the statement "WE BELIEVE DESIGN CAN CHANGE THE WORLD." Nussbaum agreed, but went on to ask "But whose design? Which solutions? What problems?" The discussions about whether or not designers can change the world became whether designers should attempt to change the world. This level of self-reflection is directly related to the growing awareness of the role of ethics in the field.

\section{Ethics in design education}

The major shifts that are occurring in contemporary design present challenges for educational institutions in terms of developing curricula and managing the proliferation of new programs that are explicitly focused on user-centered design. Service design, interaction design, design management, design for social innovation, and design for sustainability prepare students for career paths that did not exist several years ago, or maybe still do not exist today. In recognition of this fact, the AIGA posted a series of articles on its website that describe the skills that "the designers of 2015" will need: "a set of skills that include some beyond today's typical scope."(AIGA 2009b) Thirteen competences were listed in order of their ranked importance through an online survey. Many of these reflect a broader definition of design that moves careers into nontraditional domains. The most relevant to this article is number twelve in the list: "Understanding of ethics in practice." Although this statement is open-ended in that it does not spell out what 'ethics in practice' would entail, it does signals an awareness of the need for ethics training. In institutions that receive federal funding all research involving human subjects is required to secure approval from an Institutional Review Board (IRB), ${ }^{16}$ creating external pressure to include ethics training for design students who are learning to apply ethnographic methods in their research. Since private institutions are not required to have IRBs, there is little to no external pressure to include ethics in their

15 http://www.projecthdesign.org/

16 Refer to Michael Fischer's chapter "Emergent Forms of Life in Corporate Arenas" for a short discussion of IRBs in academic scholarship (Cefkin 2010). 
design curriculum.

\section{From the designer's perspective: three interviews}

Standards of practice and ethical statements from professional associations provide insight as to how the field of design is changing, but do not answer questions as to how these changes are being played out in practice on the ground. What do practicing designers think about ethics? How do ethics influence design research, especially related to the use ethnographic methods? Does design education include the subject of ethics? Questions about the ways in which ethics enter discourse and practice could only be approached through conversations with designers themselves.

The following excerpts were taken from interviews with three designers ${ }^{17}$ educated at various design schools over the past fifty years. The interviewees were selected to represent three generations of designers: from the mid-1960s, late 1980s, and first decades of the twenty-first century. Each interview provides insight as to how the understanding of ethics has evolved as the field of design and design education has changed over time.

Mid-1960s

Richard, former director of global design for a Fortune 50 firm, was educated as an industrial designer at Auburn University in the mid1960s. ${ }^{18}$ Although he did not receive ethics training while he was a student, Richard's experience reflects the central position of 'the user' in design. A practicing designer since 1970, he spoke a great deal about his experience as an undergrad design student in the mid-1960s at Auburn University where the program in industrial design was started by two dynamic young professors, graduates of the Ulm School in Germany, who introduced the so-called 'Ulm Method'. When these professors arrived the program was called 'industrial arts' and was under the School of Architecture. The Ulm School focus on user-centered systems design and rigorous process shaped the Auburn industrial design program. Students were taught that in product design designers were the 'champions' of the user. Richard noted that "It was a mission. That's why we're industrial designers." Despite the focus on 'the user', a central trope in design (Wasson 2000), ethics regarding a designer's responsibility to users, study subjects, or society at large was not covered in any of Richard's classes or in the curriculum.

\footnotetext{
17 The interviews were conducted in July 2013. The names of the interviewees have been changed. The institutions where they were educated and trained are accurate.

18 Anonymous, interviewed by Christine Miller, July 2013, Interview \#1, transcript
} 
According to Richard, the Bauhaus, which strongly influenced the Ulm School, represented a movement to return humanity to the design process. The status of design was greatly diminished in the early the years of industrial manufacturing and in the shift from craft work to mass production. The reassertion of 'human function' as well as 'manufacturing function' in the design process was a result of the influence of Bauhaus and the Ulm School. For Richard and many designers in his cohort, ethics in relation to design is about re-establishing the primacy of the human user.

Richard explained that qualitative methods are used in the work he does today, which involves corporate culture, strategy, user insights, and perception tests. The third party screeners take care of the paperwork such as informed consent forms, contracts, and photo release forms. Richard develops the content for surveys and tests, the client approves the content, and the third party collects the survey data. Richard analyzes survey data within the breakouts (categorical inquiry) prescribed by the client. The process takes about a month. Sometimes he works directly with study subjects and uses the same methodology. However, it is always a third party that handles the paperwork.

Richard continues his practice as a professional designer; he is also a part-time faculty member at an international design school. Reflecting on his career, he notes that:

[Today] the ethical concerns are focused more on sustainability and the environment and with ethics in society (for example) understand the impact of what you're doing in society at the highest level. The first Earth Day was in 1970. Designers' job of representing the human subject is still prevalent today. Designers represent the user.

\section{Late 1980s}

Tom completed a B.A. in Art Education at SUNY 'New Paltz', and an M.F.A. in Visual Communications (aka, graphic design) at the Pratt Institute in 1989. ${ }^{19}$ He recalls that he received no training in conducting ethnographic research during either his undergraduate or graduate school days. Discussions about ethics focused on professional behavior around relations with a client: expectations, roles, and responsibilities of the designer and of the client.

Tom's first job after graduate school was with a luxury brand manufacturer. He quickly became aware of the problems of 'over packaging' to make something small seem worthy of spending several hundreds of dollars. "No one that I worked with questioned that." Tom explained that his 'subversive' strategy while working in package design

19 Anonymous, interviewed by Christine Miller, July 2013, Interview \#2, transcript 
was to change the language from 'luxury' to 'elegance': small and slender versus large and heavy. He presented this idea as a way to differentiate the product from other products on the shelf and as a way to save the company as much as 15 percent on materials. As far as being successful in changing the thinking within the company, he noted that "sometimes it worked, sometimes it didn't."

In 1999 Tom applied for a faculty position in Graphic Design at an art and design school in the southeast. It was his first teaching experience. The department was in transition from an analog, mechanical/technical focus and methods of teaching to web-based graphic design, digital, and interactive design. Web design was exploding. "As a new teacher I was confronted with the responsibility to my students; it was soon clear that I had to address the things no one was talking about: overconsumption, advertising, [distorted concepts of] identity, dissatisfaction, and the role of design as a tool of advertising."

Soon after he joined the department several of the graphic design faculty "boldly introduced a critique of design practice." In 2003 Tom and other faculty introduced a course in the graduate program, "The Role of Design in Social Awareness", which until recently was a required course. Tom has since taken over directing the Design for Sustainability program and founded an international conference devoted to "changing design and design education." He also founded a 501(c)(3) non-profit organization dedicated to changing commonly held perceptions of waste materials, initially by reducing the amount of materials from the deconstruction of buildings that ended up in landfills. "What I practice now is way outside of my formal education. In retrospect, I'm surprised that I wasn't given more insight by my professors into over-consumption."

\section{$21^{\text {st }}$ Century}

Scott is currently an M.F.A. candidate in design management at a wellknown art and design school. ${ }^{20} \mathrm{His}$ undergraduate degree is in mechanical engineering. Between his undergraduate and graduate education he worked as an industrial designer in product design. While he had some ethical concerns about his role as a product designer, he explained that he became acutely aware of his responsibilities during a class project involving testing a prototype of a social innovation toolkit in the field. Through that experience he and his team were confronted with issues that surfaced while working with study participants, which gave him a new perspective on his responsibilities as a designer and researcher.

The experience during the class made him realize that he was not taught how to evaluate his responsibilities as a designer working in the social, rather than product, realm. "All discussions about ethics are around the legalities about proprietary information, not about our impact

20 Anonymous, interview by Christine Miller, July 2013, interview \#3, transcript 
on subjects." Scott cited the transition in design from the focus on object to a focus on concept: "it makes the constituent elements of what we create more potent... Designing a lamp is straight forward; designing a new voting system is not straight-forward. You need to think about how your design could disenfranchise voters, promote gerrymandering, and other issues."

According to Scott, "design research is a personal interaction; the nature of the interaction changes the way you think about your practice." He added that there should also be follow up with the participants. "There isn't enough discussion about ethics. [As designers] we work towards an outcome and move on. We don't re-engage with study participants."

When asked what design schools might do to introduce the subject of ethics, Scott replied that he did not think there should be a specific class. Instead, the discussion about ethics should be incorporated into relevant courses, particularly those involving 'social design'. This would allow for opportunities to raise questions such as "what are the conversations you're having?" or "how do you feel about the work you're doing?" He did not favor instituting a formal oversight board like an IRB (Institutional Review Board), which he felt might take the responsibility for decisions out of the designer's purview. Instead, he preferred something akin to mentorship rather than oversight.

In closing, Scott noted that "the scope of design ethics has become much broader. Professional practice must change, as must design education. I don't see this happening anywhere."

Taken collectively these interviews present a shifting sense of ethical responsibility, from a primary concern for the client to a concern for the 'user' and, currently, to understanding the impact of one's work in society at the highest level. Over time a new sense of responsibility and accountability influences design practice, including the ways in which these interviewees think about ethics in their practice and in research conducted with human subjects ('users'). Despite the small sample the interviews provide insight into both individual designers' perspectives regarding ethics and how they were introduced to the topic in their education and through their professional careers.

\section{Re-contextualizing ethnography and ethics in design}

Naturalistic inquiry and ethnographic-style research have become staples of design research. As the scope of design has broadened beyond aesthetic considerations and usability testing the domain of practice has broadened to bring designers in direct and often intimate contact with 'users' who are the subjects of their research. Meanwhile, the domain of practice for anthropologists has also shifted, bringing many applied 
anthropologists into multiple discipline teams (Choi and Pak 2006) ${ }^{21}$ where they work side-by-side with designers. Although they might be working on the same teams, anthropologists and designers come from distinctly different histories in regards to ethics, ethnography, and ethics training. And while anthropology and design share a human-centered perspective, fundamental differences remain in the goals of their practice. Whether the design challenge is a tangible object - such as tents for a refugee camp - or an intangible - for example, a model for analyzing complex data through visualization - the goal of design is to solve problems by engaging in a process to generate insights that inform the design of prototypes of possible solutions. An anthropologist approaching the same problems would likely conduct a rigorous holistic study of the context and individuals involved, identifying multiple factors that impact the current situation to develop findings that would then be used to inform decision making.

Unlike anthropology, where the focus of study has always been on human subjects and their interaction within and with the environment, the focus of design has been on the production of material culture and creation of the built environment. ${ }^{22}$ The shift in design from a focus on the 'object' to 'the user' is changing the way that designers think about ethics. In traditional design practice, ethics was primarily concerned with plagiarism and the relationship between the designer and client specifically, protecting proprietary information. As designers take an active role in engaging directly with users to understand their needs, desires, behaviors, and motivations it is likely that ethical issues related to privacy, informed consent, and sharing of research data will become more pressing. That said, it is unlikely that ethical concerns will assume the same position in design research as they do in anthropological practice. Instead, ethics in design may continue to evolve around the issues of accountability and the impact or consequences of the end product or service on people and the planet.

\section{Converging and emerging fields}

Teams comprised of members from diverse disciplinary backgrounds are increasingly being deployed in various fields. Despite the associated problems - such as negotiating shared working practices, tools, and language across disciplinary boundaries - multiple discipline teams have achieved successful outcomes. With the urgent need to solve ever more

21 Choi and Pak (2006) emphasize the distinction between multi-, inter- and trans-disciplinary teams. Instead, the term "multiple discipline teams" is used to emphasize the differences.

22 In reviewing the portfolio of an industrial design student, especially at the undergraduate level, it is not unusual to see impressive renderings of material objects represented without any association to a person, as if they had emerged and exist detached from both social and physical context. 
complex problems they will continue to be of interest within all types of organizations and settings. In the process of working their together tools and methods are being exchanged, new concepts are emerging, and theoretical frameworks are being articulated. Even as learning often emerges out of situations of conflict, standards of professional practice are being raised, and the potential for more comprehensive theoretical perspectives is being realized.

We are no longer working in isolated disciplinary silos. As the practice of ethnography continues to diffuse we can expect that it will be re-contextualized to adapt to specific disciplinary perspectives and research objectives. New ethnographic methods will be invented to incorporate the research objectives of multiple discipline teams. Given the current trend, it is likely that the associated ethical concerns for human subjects will take on more importance in design education. As this article has suggested, the sensitivity to ethical issues in the field of design has evolved through a complex process involving the long term shift in focus from 'object' to 'user' and the consequent expansion of the domain of design practice into new areas, such as design for social innovation, where designers inhabit the field with anthropologists and other researchers.

From the vantage point of an anthropologist working in the field of design education it has been interesting to notice many similarities between the historical trajectories of design and anthropology as fields of practice and, more recently, in the arenas where they are converging. The practice of ethnography as it has diffused, and is now diffusing, across multiple fields and professions is at the confluence of this trend. How ethical concerns are addressed and how they evolve in unique ways in the "'hybrid' approach"' (Baba 2005) that is characteristic of ethnographic practice in design research is a story that remains in the making.

\section{References}

AAA. 2012. Statement on Ethics: Principles of Professional Responsibility. Arlington, VA: Anthropological Association American.

AIGA. 2009a. Design Business + Ethics. In AIGA Design Business and Ethics J. Stone, L. Rigsby, A. Haley, S. Berlow, M. Carter, J. Hoefler, Z. Licko, F.M. Holland, T. Shannon, D. Abraham, M. Barbey, T. Crawford, J. Faris, and S. Perkins, eds. New York: Richard Grefé, AIGA.

AIGA. 2009b. Designer of 2015 Competencies, Vol. 2013: AIGA.

Baba, Marietta. 2005. To the End of Theory-Practice 'Apartheid': Encountering the World. Ethnographic Praxis in Industry Conference, Seattle, WA, 2005. Vol. 1, pp. 205-217. American Anthropological Association. 
Beyer, Hugh, and Karen Holtzblatt. 1998. Contextual Design: Defining Customer-Centered Systems. New York: Morgan Kaufmann Publishers.

Cefkin, Melissa, ed. 2010. Ethnography and the Corporate Encounter: Reflections on Research in and of the Corporation. Volume 5. New York: Berghahn Books.

Choi, Bernard C.K., and Anita W.P. Pak. 2006. Multidisciplinarity, interdisciplinarity and transdisciplinarity in health research, services, education and policy: 1 . Definitions, objectives, and evidence of effectiveness. Clinical \& Investigative Medicine 29(4):351-364.

Eames, Charles and Ray. 1972. Design Q\&A.

Holtzblatt, Karen, and S. Jones. 1995. Conducting and Analyzing a Contextual Interview. In Readings in Human-Computer Interaction: Toward the Year 2000. R.M. Baecker, J. Grudin, W.A.S. Buxton, and S. Greenberg, eds. San Francisco: Morgan Kaufman.

IDSA. 2010. IDSA Code of Ethics.

Neuhart, John, et al. 1989. Eames Design: The work of the office of Charles and Ray Eames. New York: H.N. Abrams.

Nussbaum, Bruce. 2010. Is Humanitarian Design the New Imperialism? In Fast Company Design, Vol. 2013: Fast Company.

Wasson, Christina. 2000. Ethnography in the Field of Design. Human Organization 59(4):377-388.

Christine Miller, Ph.D., is a professor in the graduate program in Design Management at the Savannah College of Art and Design (SCAD). Her interdisciplinary doctoral research (Anthropology and Management) explored process formalization and the relationship between innovation and formalization at a Tier One automotive supplier. Miller's research interests incorporate how sociality and culture influence the design and diffusion of new products, processes, and technologies. She studies technology-mediated communication within groups, teams, and networks and the emergence of co-located and technology-enabled collaborative innovation networks (COINs). Miller participates in several working groups that foster multi-, inter-, and trans-disciplinary practice and is a founding member of the COINs conference. The author may be reached atczmiller01@me.com 